\title{
BMJ Open Near-vision impairment and effective near-vision spectacle coverage in two districts in Telangana, India: a population-based cross-sectional study
}

\author{
Srinivas Marmamula (D) , ${ }^{1,2,3,4}$ Jill Keeffe, ${ }^{4}$ Rajesh Challa, ${ }^{4}$ Javed Mohd, ${ }^{4}$ \\ Rohit C Khanna (i) ${ }^{3,4}$
}

To cite: Marmamula S, Keeffe J, Challa R, et al. Near-vision impairment and effective nearvision spectacle coverage in two districts in Telangana, India: a population-based crosssectional study. BMJ Open 2021;11:e047131. doi:10.1136/ bmjopen-2020-047131

- Prepublication history for this paper is available online. To view these files, please visit the journal online (http://dx.doi org/10.1136/bmjopen-2020047131).

Received 20 November 2020 Revised 27 February 2021 Accepted 16 March 2021
Check for updates

(C) Author(s) (or their employer(s)) 2021. Re-use permitted under CC BY-NC. No commercial re-use. See rights and permissions. Published by BMJ.

For numbered affiliations see end of article.

Correspondence to Dr Srinivas Marmamula; sri.marmamula@lvpei.org

\section{ABSTRACT}

Objectives To investigate the prevalence of near-vision impairment (NVI) and effective spectacle coverage for near vision in those aged $\geq 40$ years in Khammam and Warangal district in Telangana, India.

Design A population-based cross-sectional study. Setting Khammam and Warangal district in Telangana, India.

Participants Of 6000 people enumerated, 5357 were examined (89\%). 4526 participants without distance vision impairment were included in the analysis.

Main outcome measures The study teams visited selected households and conducted eye examinations. NVI was defined as binocular presenting near vision worse than N6. 'Unmet need' was deemed to be present if the unaided near vision was worse than N6 and improved to N6 with near correction among the participants who did not have spectacles for near vision. 'Met need' was deemed to be present when unaided near vision was worse than N6 but improving to N6 with their spectacles. The 'undermet need' was deemed to be present when aided near vision was worse than $\mathrm{N} 6$ but improved to $\mathrm{N} 6$ with correction. Based on these definitions, e-nearvision coverage (\%) is calculated as follows: e-NVC $(\%)=$ metneed $/($ met need+undermet need+unmetneed) $\times 100$.

Results The mean age was 53.5 years (SD: 10.8 years), $2534 / 4526$ (55.8\%) were women, $1819 / 4526(41.8 \%)$ had at least primary school education and 2368/4526 (52.3\%) were from the Khammam district. The prevalence of NVI was $55.8 \%$ (95\% $\mathrm{Cl} 72.5$ to $75.1 ; \mathrm{n}=3343$ ). Overall, the e-NVC (\%) was $31.8 \%$. It was $40.0 \%$ in Khammam and $23.2 \%$ in Warangal.

Conclusion NVI is common in Khammam and Warangal districts in Telangana with inadequate effective near-vision coverage. Effective service delivery models are needed to reach out and provide services to address NVI to achieve universal eye health coverage in the region.

\section{INTRODUCTION}

Near-vision impairment (NVI) is a public health challenge that impacts over a billion people globally. ${ }^{1}$ The issue of NVI is gaining importance in the recent past as studies indicate a high prevalence with an adverse effect
Strengths and limitations of this study

- Large population-based study design that achieved a good response rate and covered two large districts in the state of Telangana in India.

- Nearly a third of the individuals aged $\geq 40$ years with no distance vision loss had near vision impairment in Warangal and Khammam in Telangana, India.

- We have excluded participants with distance visual impairment that might have affected our estimation of near-vision impairment.

- The inability to do refraction during the study could be a limitation.

on the visual functions of people in different settings $^{2-10}$ The economic impact of uncorrected presbyopia and also improvement in productivity on the provision of near vision spectacles has been reported. ${ }^{11}{ }^{12}$ As a recognition of its importance, NVI is now included in the categories of vision impairment. ${ }^{13} \mathrm{~A}$ vast majority of the NVI is due to presbyopia, which is an age-related condition. With an increasing proportion of the elderly in most populous countries such as India, the prevalence and the number of people with NVI is likely to increase over time unless appropriate strategies are put in place.

Fortunately, a large proportion of NVI can be corrected with a pair of spectacles. NVI has been widely studied in the past years. ${ }^{5} 814-17$ NVI is known to have significant regional variability, and local studies are needed to estimate its prevalence. ${ }^{18}$ Universal health coverage (UHC), as defined by WHO, encompasses preventive, promotive, curative and rehabilitation components of care delivered to people without incurring financial hardships. ${ }^{19}$ Universal eye health (UEH) forms the integral part of $\mathrm{UHC}^{20} \mathrm{UEH}$ aims to address avoidable vision loss including NVI. Spectacles coverage (\%) is commonly used as 
an impact indicator for refractive error services and also for presbyopia. Recently, new indicators such as effective refractive error coverage $(\%)$ and refractive error coverage have been proposed, which can also be used as an indicator for NVI. ${ }^{21}$ Several service delivery models such as the vision centre model are being implemented to provide primary eye care including the provision of spectacles for uncorrected refractive errors and NVI in India. ${ }^{22}{ }^{23}$ Knowing the prevalence of NVI and impact indicators such as near-vision coverage and effective nearvision coverage can help in planning and monitoring of primary eye care services to achieve universal eye health coverage.

A large population-based cross-sectional study was undertaken among individuals aged 40 years and older in two large districts in the state of Telangana in India, using the Rapid Assessment of Visual Impairment methodology. ${ }^{24} 25$ The temporal trends in the prevalence and causes of visual impairment and spectacles use and coverage for refractive errors for distance were published. ${ }^{26} 27$ In this paper, we report on NVI and effective near spectacle coverage for near vision in this population.

\section{MATERIALS AND METHODS Ethics approval}

The study protocol adhered to the tenets of the Declaration of Helsinki. Written informed consent was obtained from each participant before enrolment in the study.

The study was carried out in Warangal and Khammam districts in Telangana during the year 2017. Khammam and Warangal are the large neighbouring districts in the Telangana state with a population of 2.9 million and 3.5 million, respectively. Both the districts are predominantly rural, and agriculture is the main occupation. The literacy rate in both the districts is around $65 \%$ as per the 2011 census. The details of the sample selection protocols are described in previous publications. ${ }^{26}{ }^{27}$ In short, cluster random sampling method was used to select the clusters in both the districts. In each cluster, 50 individuals aged 40 years and older were enumerated, and all those who were available were examined. ${ }^{25}$ This study was nested in a larger study that was aimed to assess the prevalence and causes of distance visual impairment in this population and had an adequate sample size to assess the prevalence of NVI. ${ }^{2627}$

\section{Data collection}

The data collection protocol is described in earlier publications. ${ }^{26}{ }^{27}$ In short, a team comprising a trained vision technician and a community eye health fieldworker visited the households in the selected clusters and conducted eye examinations. Three teams were involved in the data collection. A reliability study was set up to assess the agreement between the examiners for visual acuity assessment, and the three teams had a minimum kappa of 0.6 with a gold standard optometrist.
Personal and demographic information such as age, gender, education and use of spectacles were collected. Distance visual acuity was assessed at a distance of 6 m using a standard Snellen chart, monocularly and in ambient lighting conditions. Near vision was assessed binocularly at a fixed distance of $40 \mathrm{~cm}$ using an $\mathrm{N}$ notation chart with tumbling E optotypes, in good lighting conditions. If a participant reported using spectacles for near vision, then the vision was assessed with spectacles, in addition to unaided near vision. If the presenting near vision was worse than N6, then it was reassessed with a near addition lens appropriate to the age of the participant. This was considered as best-corrected near vision as described in previous publications. ${ }^{1725}$ Multiple random visits were made to the field sites to monitor the data collection and verify the findings. All the records were reviewed before leaving the field to ensure the completeness of the forms.

\section{Definitions}

NVI was defined as binocular presenting near vision worse than $6 / 12(\mathrm{~N} 6)$. This was further categorised as mild NVI $(<6 / 12-6 / 18$; N8-N10), moderate NVI $(<6 / 18-6 / 60$; N12-N32) and profound NVI (worse than 6/60; worse than N32). Similar definitions were used in a multicentre study on NVI. ${ }^{518}$ In line with other studies, functional presbyopia was defined as presenting near vision worse than N8 (6/15) and improving to at least N8 or better with near addition. ${ }^{14} 172829$

The effective near-vision coverage (e-NVC) was calculated using similar methods proposed for effective distance refractive error coverage calculation described by McCormick and colleagues. ${ }^{21}$ 'Unmet need' was deemed to be present if the unaided near vision worse than N6 and improved to $\mathrm{N} 6$ on near correction among the participants who did not have spectacles for near vision. 'Met need' was deemed to be present when unaided near vision was worse than N6 but improving to N6 with their spectacles. The 'undermet need' was deemed to be present when aided near vision was worse than N6 but improved to $\mathrm{N} 6$ with correction. Based on these definitions, e-NVC $(\%)$ is calculated as follows: e-NVC $(\%)=$ met need / (met need+undermet need+unmet need) $\times 100$.

NVC (\%) coverage was also estimated where the undermet need is added to the numerator. ${ }^{21}$ NVC (\%) is calculated as follows: NVC $(\%)=$ met need+under met need / (met need+under met need+unmetneed) x 100 . NVC (\%) is intended to measure the UHC element of access to NVI care. This is similar to the spectacle coverage (\%) for near vision described in the earlier studies. ${ }^{141729}{ }^{30}$ Based on e-NVC (\%) and NVC (\%), relative quality gap (RQG-NVC (\%)) is calculated as follows: RQG-NVC $(\%)=1-(\mathrm{e}-\mathrm{NVC}(\%) / \mathrm{NVC}(\%))$.

\section{Patient and public involvement}

Patients and public were not involved in the design and the conduct of the study. 


\section{Data management}

Data analysis was carried out using Stata statistical software V.14. ${ }^{31}$ The participants with distance visual impairment were not included in the analysis. Prevalence of presenting, unaided and best-corrected NVI was calculated and presented with $95 \%$ CIs. A $\chi^{2}$ test was used for categorical variables, and a Student's t-test was used for continuous variables. Multivariable analysis was done using multiple logistic regression analyses to assess the factors associated with NVI. The ORs with 95\% CIs are presented. The model fit was assessed using the HosmerLemeshow test for goodness of fit. A p value of $<0.05$ was considered significant for all the estimates.

\section{RESULTS}

\section{Characteristics of the participants}

In total, 6000 participants aged $\geq 40$ years were enumerated, and $5357(89 \%)$ were examined from 120 study clusters. Eight hundred and thirty-one of 5357 (15.5\%) participants who had distance visual impairment (presenting visual acuity worse than $6 / 18$ in the better eye) were excluded from the analysis. Of the remaining, 4526 participants included in the analysis, the mean age was 53.5 years (SD: 10.8 years), 2534 (55.8\%) were women, $1819(41.8 \%)$ had any degree of education and 2368 (52.3\%) were from the Khammam district. The mean age of the participants examined in Warangal was marginally higher in Khammam ( 54.6 years vs 52.4 years; $\mathrm{p}<0.05$ ). There was no statistically significant difference in the proportion of men and women examined in these districts $\left(\chi^{2}\right.$ test; $\left.p=0.53\right)$.

\section{NVI and associations with sociodemographic characteristics}

Based on presenting near vision, the prevalence of NVI was $55.9 \%$ (95\% CI 54.3 to 57.3 ; $\mathrm{n}=2528$ ). On univariable analysis, NVI varied significantly across the age groups and was highest in the oldest age group $(71.9 \%)$ and the least in the 40-49years age group (50.8\%). NVI was higher among women compared with men $59.9 \%$ vs $50.8 \% ; \mathrm{p}<0.01)$. It was higher among those who were not educated $(\mathrm{p}<0.01)$ and also among those who lived in Warangal district $(\mathrm{p}<0.01)$ (table 1$)$.

On applying multiple logistic regression analysis, compared with those aged 40-49 years, the odds of NVI were significantly higher in the 60-69 years age group (OR: $1.40 ; 95 \%$ CI 1.18 to 1.66 ) and the highest in the oldest age groups (OR: 2.20; $95 \%$ CI 1.75 to 2.75). Women had a significantly higher odds for NVI compared with men (OR: $1.21 ; 95 \%$ CI 1.06 to 1.38 ). Similarly, those who had no education had higher odds for NVI compared with those who had any level of education (OR: 1.81; $95 \%$ CI 1.6 to 2.06). The odds for NVI were higher for those residing in the Warangal district compared with those from Khammam district (OR: 1.33; 95\% CI 1.18 to 1.50) (table 2).

\section{Categories of NVI and functional presbyopia}

The prevalence of NVI based on unaided, presenting and best-corrected near vision were $73.8 \%$ (95\% CI 72.5 to
Table 1 The characteristics of the study participants and the prevalence of near vision impairment $(n=4526)$

\begin{tabular}{|c|c|c|c|}
\hline & \multirow{2}{*}{$\begin{array}{l}\text { Total in the } \\
\text { sample }\end{array}$} & Near-vision impairment & \multirow[b]{2}{*}{$P$ value } \\
\hline & & n (\%; 95\% Cls) & \\
\hline \multicolumn{2}{|c|}{ Age group (years) } & & $<0.01$ \\
\hline $40-49$ & 1970 & $1001(50.8 ; 48.6$ to 53.0$)$ & \\
\hline $50-59$ & 1236 & $665(53.8 ; 51.0$ to 56.6$)$ & \\
\hline $60-69$ & 857 & $529(61.7 ; 58.4$ to 65.0$)$ & \\
\hline $\begin{array}{l}70 \text { and } \\
\text { above }\end{array}$ & 463 & $333(71.9 ; 67.6$ to 76.0$)$ & \\
\hline Gender & & & $<0.01$ \\
\hline Male & 2002 & $1017(50.8 ; 48.6$ to 53.0$)$ & \\
\hline Female & 2524 & $1511(59.9 ; 57.9$ to 61.8$)$ & \\
\hline \multicolumn{2}{|l|}{ Education level } & & $<0.01$ \\
\hline $\begin{array}{l}\text { No } \\
\text { education }\end{array}$ & 2635 & $1668(63.3 ; 61.4$ to 65.1$)$ & \\
\hline $\begin{array}{l}\text { Any } \\
\text { education }\end{array}$ & 1891 & $860(45.5 ; 43.2$ to 47.8$)$ & \\
\hline \multicolumn{2}{|c|}{ Place of residence } & & $<0.01$ \\
\hline Khammam & 2368 & $1224(51.7 ; 50.0$ to 53.7$)$ & \\
\hline Warangal & 2158 & $1304(60.4 ; 58.3$ to 62.5$)$ & \\
\hline Total & 4526 & 2528 (55.9; 54.4 to 57.3$)$ & \\
\hline
\end{tabular}

75.1), $55.8 \%$ (95\% CI 56.4 to 57.3) and 15.7 (95\% CI 14.7 to 18.8$)$, respectively. While the NVI based on unaided near vision was similar in both districts $(\mathrm{p}=0.39)$; based on presenting and best-corrected vision, the prevalence was higher in Warangal compared with Khammam $(\mathrm{p}<0.01)$ (table 3). Prevalence of functional presbyopia was $41.1 \%$ (95\% CI 39.0 to 42.5$)$. It was significantly similar in Khammam compared with the Warangal district $(40.1 \%$ vs $42.1 \%$; $\mathrm{p}=0.144)$.

Based on presenting near vision, 1876 (44.1\%; 95\% CI 40.9 to 42.9$)$ had mild NVI, 639 (14.2\%; 95\% CI 13.1 to 15.2) had moderate NVI and $13(0.3 \%$; $95 \%$ CI 0.1 to $0.5)$ participants had profound NVI. The categories of NVI varied significantly by district of residence $(p<0.01)$ (figure 1).

\section{e-NVC (\%) for NVI}

Overall, the e-NVC (\%) was $31.8 \%$, NVC (\%) was $33.1 \%$ and NVC (\%) gap was 4.1\%. The e-NVC (\%) and NVC (\%) were higher in Khammam, but NVC (\%) gap was higher in Warangal, suggesting better quality and coverage in Khammam compared with that of Warangal (table 4).

\section{DISCUSSION}

Over $55 \%$ of the participants examined had NVI with a significantly higher prevalence in the Warangal district compared with that of Khammam. Our previous research reported a higher prevalence of visual impairment for distance in Warangal, which has continued to remain higher in subsequent studies. ${ }^{27}$ An improvement in spectacles coverage $(\%)$ for distance vision was reported in 
Table 2 Multivariable analysis showing the association between near visual impairment and sociodemographic variables (multiple logistic regression analysis; $n=4526$ )

\begin{tabular}{|c|c|c|}
\hline & OR (95\% Cl) & $\begin{array}{l}\text { Statistical } \\
\text { significance } \\
\text { (P value) }\end{array}$ \\
\hline \multicolumn{3}{|l|}{ Age group (years) } \\
\hline $40-49$ & Reference & \\
\hline $50-59$ & $1.04(0.90$ to 1.21$)$ & 0.58 \\
\hline $60-69$ & 1.40 (1.18 to 1.66$)$ & $<0.01$ \\
\hline 70 and above & 2.20 (1.75 to 2.75$)$ & $<0.01$ \\
\hline \multicolumn{3}{|l|}{ Gender } \\
\hline Male & Reference & \\
\hline Female & 1.21 (1.06 to 1.38$)$ & $<0.01$ \\
\hline \multicolumn{3}{|l|}{ Education } \\
\hline Any education & Reference & \\
\hline No education & 1.81 (1.6 to 2.06$)$ & $<0.01$ \\
\hline \multicolumn{3}{|l|}{ Place of residence } \\
\hline Khammam & Reference & \\
\hline Warangal & 1.33 (1.18 to 1.50$)$ & $<0.01$ \\
\hline
\end{tabular}

Khammam district. ${ }^{26}$ There is no comparative data available for NVI in these districts. Availability and uptake of services could be one important reason, as LVPEI has an integrated network of primary eye care centres in Khammam in contrast to no such network in Warangal. Other risk factors of presbyopia such as ambient temperature and geographical altitude are similar in both the districts. ${ }^{32-35}$

Similar to other studies in this region, we found a higher prevalence of NVI in these two districts, which can possibly be attributed to poor uptake of services. The association between gender and NVI had been inconsistent across the studies in this region. While Nirmalan and colleagues found a positive association between gender and NVI similar to the present study, ${ }^{36}$ other populationbased studies from Telangana showed no such association. The multicentre study that included seven sites including a site in South India also did not find an association between gender and NVI. ${ }^{18}$ Gender was also not found to be associated with NVI in studies carried out in China and Brazil. ${ }^{5} 37$

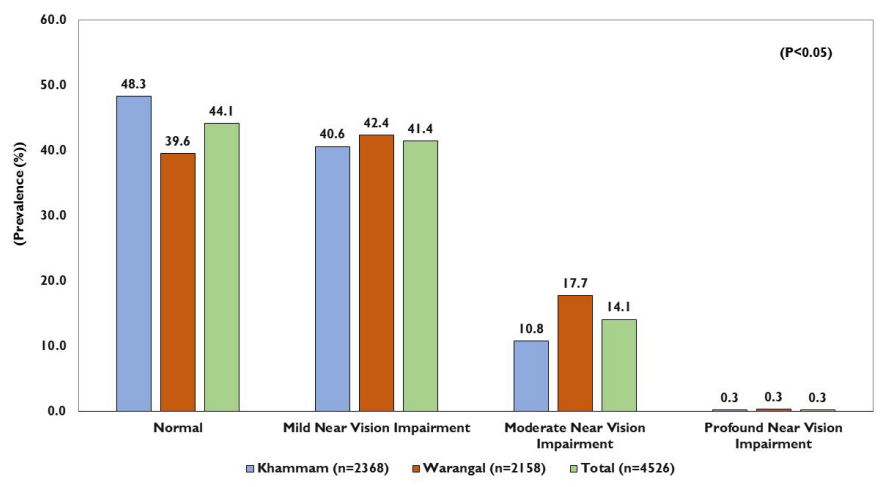

Figure 1 Categories of near-vision impairment stratified by the district of residence.

As reported in a meta-analysis on presbyopia and gender, the varying prevalence of NVI could be related to the felt need and uptake of services and not to physiological differences in accommodation. ${ }^{38}$ Consistent with other studies, we found a significant association between NVI and education. NVI was higher among those with no education. Education could be an indicator of a better socioeconomic status and therefore seeking eye care. Also, those who read may have a greater 'felt need' for visual correction for near work and seek eye care services. Though Nirmalan et al found no association between education and presbyopia, other studies have found a significant association between lack of education and NVI, similar to our study. ${ }^{142829}$ The seven site multicountry study found no association between NVI and education. ${ }^{18}$ Studies done in other regions of the world such as Brazil, South Africa and China also revealed varying prevalence of NVI with education. ${ }^{51637}$

We found that a large proportion of NVI is in the mild category. It is possible that the impact of this grade of NVI is not significant for functioning and hence remained uncorrected. Our study was carried out in rural locations where most of the population is involved in unskilled occupations with limited demand for very good near vision. The NVC (\%), which is also referred to as spectacle coverage for near, was higher in Khammam compared with that of Warangal. It was also higher compared with a previous study in Telangana where it was reported as $26.5 \% .{ }^{17}$ The spectacle coverage of $23.2 \%$ in Warangal was even lower that reported from Telangana. There is variation in the coverage in Khammam and Warangal,

Table 3 NVI based on unaided, presenting and best-corrected near vision stratified by the district of residence

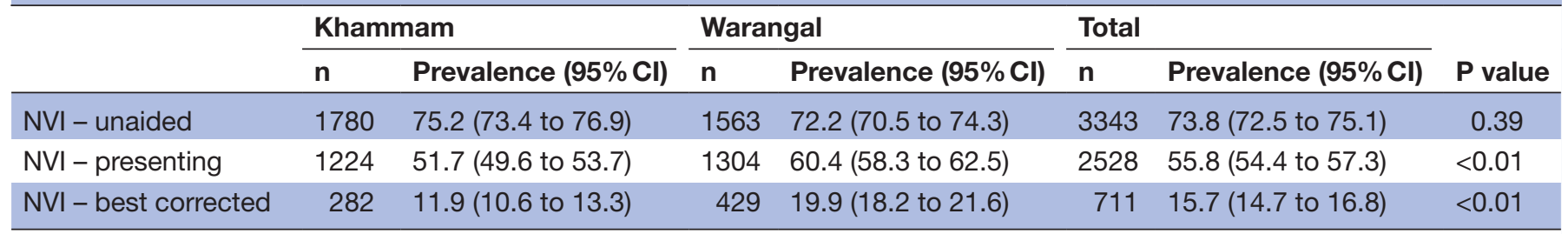

$\mathrm{NVI}$, near-vision impairment. 
Table 4 Effective near vision coverage (e-NVC (\%)), near vision coverage (NVC (\%)) and near vision coverage quality gap stratified by the district of residence

\begin{tabular}{lllllll}
\hline & $\begin{array}{l}\text { Met } \\
\text { need }(\mathbf{n})\end{array}$ & $\begin{array}{l}\text { Undermet } \\
\text { need }(\mathbf{n})\end{array}$ & $\begin{array}{l}\text { Unmet } \\
\text { need (n) }\end{array}$ & e-NVC (\%) & NVC (\%)† & NVC - quality gapł \\
\hline Khammam & 380 & 13 & 556 & 40.0 & 41.4 & 3.3 \\
Warangal & 211 & 12 & 688 & 23.2 & 24.5 & 5.4 \\
Overall & 591 & 25 & 1244 & 31.8 & 33.1 & 4.1 \\
\hline
\end{tabular}

${ }^{*}$ e-NVC $(\%)=($ met need/met need+undermet need+unmet need $) \times 100$. †NVC $(\%)=($ met need+under met need/met need+undermet need+unmet need $) \times 100$. $\ddagger N V C-$ gap $=1-(e-N V C / N V C) \times 100$.

suggestive of a difference in availability and uptake of services between the districts. Also, a smaller NVC (\%) quality gap suggests a low undermet need for NVI in both the districts. The presence of a small difference between e-NVC (\%) and NVC (\%) suggests that there are no major issues related to the quality of services for near, which is a welcome finding. Correction of NVI is relatively straightforward unlike distance refractive errors; hence less prone to quality-related issues.

The prevalence of functional presbyopia varies significantly between the regions mainly due to differences in the definitions used and the age groups studied. The prevalence ranges from $70 \%$ in East Africa to $30 \%$ in Nigeria. ${ }^{5} 714293639$ The prevalence of functional presbyopia was $44.1 \%$ in our study compared with $54.6 \%$ in Telangana using a similar protocol and age group classification. ${ }^{17}$ The variation in the prevalence of functional presbyopia could be attributed to several factors including cataract, which may induce index myopia resulting in better near vision. Also, we found that a small proportion of participants had profound near vision impairment that could be attributed to early cataractous changes, especially posterior subcapsular cataract or posterior segment pathology.

As the goal of universal eye health is to increase the coverage of services aligned as closely as possible with no financial hardship, there is a definite need to develop strategies to provide refraction services. The pyramidal model developed and implemented in the states of Telangana, Andhra Pradesh, Odisha and other parts of India appears to be an effective model to address vision loss and provide primary eye care including refraction and spectacles dispensing services. ${ }^{26}$ Such models need a wider replication to achieve the goal of UEH.

The strength of our study includes a large populationbased sample size randomly selected from two highly populated districts in the Telangana state. We reported impact indicators such as NVC (\%), which are reported to be useful for planning and monitoring of eye care services. The results from our study could be generalised to larger populations in the districts. We have excluded participants with distance visual impairment that might have affected our estimation of NVI. The inability to do refraction during the study could be a limitation. Another limitation was the inability to control the external lighting while assessing near vision in a field setting. Though every effort was made to ensure good lighting, it could have varied across the measurements. In conclusion, our study has provided valuable insights into the NVI and effective spectacle coverage in two large districts in the state of Telangana in India, which can now be used as a baseline for the planning and monitoring of primary eye care services in the region.

\section{Author affiliations}

${ }^{1}$ Brien Holden Institute of Optometry and Vision Science, L V Prasad Eye Institute, Hyderabad, India

${ }^{2}$ Wellcome Trust, Department of Biotechnology India Alliance, L V Prasad Eye Institute, Hyderabad, India

${ }^{3}$ School of Optometry and Vision Science, University of New South Wales, Sydney, New South Wales, Australia

${ }^{4}$ Allen Foster Community Eye Health Research Centre, Gullapalli Pratibha Rao International Centre for Advancement of Rural Eye care, L V Prasad Eye Institute, Hyderabad, India

Acknowledgements The authors would like to thank the volunteers for their participation in the study. The authors would also like to thank Guvvala Venkatesh, Buhyavarapu Sanjay Bhargav, Yellimalla Srikanth, Kolakaluri Praveen Kumar and Seelam Siva Nagaraju (vision technicians) for the assistance provided in data collection, Ratnakar Yellapragada for support in data management and Dr Sreedevi Yadavalli for language inputs in earlier versions of our manuscript.

Contributors SM conceived the idea, designed and conducted the study, analysed the data and wrote the manuscript. RC and JM assisted in data collection, clinical quality control and supervised the field activities. JK and RCK reviewed the earlier version of the manuscripts and provided intellectual inputs.

Funding This work was supported by Hyderabad Eye Research Foundation, India, and Lions Clubs International Foundation (LCIF), SightFirst Research grant (SF 1943/ UND).

Competing interests None declared.

Patient consent for publication Not required.

Ethics approval The study protocol was approved by the Institutional Review Board of Hyderabad Eye Research Foundation, L V Prasad Eye Institute.

Provenance and peer review Not commissioned; externally peer reviewed. Data availability statement № data are available.

Open access This is an open access article distributed in accordance with the Creative Commons Attribution Non Commercial (CC BY-NC 4.0) license, which permits others to distribute, remix, adapt, build upon this work noncommercially, and license their derivative works on different terms, provided the original work is properly cited, appropriate credit is given, any changes made indicated, and the use is non-commercial. See: http://creativecommons.org/ licenses/by-nc/4.0/.

\section{ORCID iDs}

Srinivas Marmamula http://orcid.org/0000-0003-1716-9809

Rohit C Khanna http://orcid.org/0000-0002-8698-5562 


\section{REFERENCES}

1 Holden BA, Fricke TR, Ho SM, et al. Global vision impairment due to uncorrected presbyopia. Arch Ophthalmol 2008;126:1731-9.

2 Laviers $\mathrm{H}$. The prevalence of presbyopia and the feasibility of community distribution of near spectacles in adults in Zanzibar, East Africa. Community Eye Health 2007;20:73.

3 Laviers HR, Omar F, Jecha H, et al. Presbyopic spectacle coverage, willingness to pay for near correction, and the impact of correcting uncorrected presbyopia in adults in Zanzibar, East Africa. Invest Ophthalmol Vis Sci 2010;51:1234-41.

4 Lu Q, Congdon N, He X, et al. Quality of life and near vision impairment due to functional presbyopia among rural Chinese adults. Invest Ophthalmol Vis Sci 2011;52:4118-23.

5 Lu Q, He W, Murthy GVS, et al. Presbyopia and near-vision impairment in rural Northern China. Invest Ophthalmol Vis Sci 2011;52:2300-5.

6 Patel I, Munoz B, Burke AG, et al. Impact of presbyopia on quality of life in a rural African setting. Ophthalmology 2006;113:728-34.

7 Patel I, West SK. Functional presbyopia in Kenya. Clin Exp Ophthalmol 2008;36:699-700.

8 Sherwin JC, Keeffe JE, Kuper $\mathrm{H}$, et al. Functional presbyopia in a rural Kenyan population: the unmet presbyopic need. Clin Exp Ophthalmol 2008;36:245-51.

9 du Toit R, Palagyi A, Ramke J, et al. The impact of reduced distance and near vision on the quality of life of adults in Timor-Leste. Ophthalmology 2010;117:2308-14.

10 Sapkota YD, Dulal S, Pokharel GP, et al. Prevalence and correction of near vision impairment at Kaski, Nepal. Nepal J Ophthalmol 2012;4:17-22.

11 Smith TST, Frick KD, Holden BA, et al. Potential lost productivity resulting from the global burden of uncorrected refractive error. Bull World Health Organ 2009;87:431-7.

12 Reddy PA, Congdon N, MacKenzie G, et al. Effect of providing near glasses on productivity among rural Indian tea workers with presbyopia (prosper): a randomised trial. Lancet Glob Health 2018;6:e1019-27.

13 Flaxman SR, Bourne RRA, Resnikoff S, et al. Global causes of blindness and distance vision impairment 1990-2020: a systematic review and meta-analysis. Lancet Glob Health 2017;5:e1221-34.

14 Marmamula S, Narsaiah S, Shekhar K, et al. Presbyopia, spectacles use and spectacle correction coverage for near vision among cloth weaving communities in Prakasam district in South India. Ophthalmic Physiol Opt 2013;33:597-603.

15 Mashayo ER, Chan VF, Ramson P, et al. Prevalence of refractive error, presbyopia and spectacle coverage in Kahama district, Tanzania: a rapid assessment of refractive error. Clin Exp Optom 2015;98:58-64.

16 Naidoo KS, Jaggernath J, Martin C, et al. Prevalence of presbyopia and spectacle coverage in an African population in Durban, South Africa. Optom Vis Sci 2013;90:1424-9.

17 Marmamula S, Khanna RC, Kunuku E, et al. Near visual impairment and spectacle coverage in Telangana, India. Clin Exp Ophthalmol 2017:45:568-74.

$18 \mathrm{He} \mathrm{M,} \mathrm{Abdou} \mathrm{A,} \mathrm{Naidoo} \mathrm{KS,} \mathrm{et} \mathrm{al.} \mathrm{Prevalence} \mathrm{and} \mathrm{correction}$ of near vision impairment at seven sites in China, India, Nepal, niger, South Africa, and the United States. Am J Ophthalmol 2012;154:e101:107-16.

19 Verrecchia R, Thompson R, Yates R. Universal health coverage and public health: a truly sustainable approach. Lancet Public Health 2019;4:e10-11.
20 The Lancet. A vision for universal eye health. The Lancet 2019;394:1388.

21 McCormick I, Mactaggart I, Bastawrous A, et al. Effective refractive error coverage: an eye health indicator to measure progress towards universal health coverage. Ophthalmic Physiol Opt 2020;40:1-5.

22 Rao GN. The Barrie Jones Lecture-Eye care for the neglected population: challenges and solutions. Eye 2015;29:30-45.

23 Rao GN, Khanna RC, Athota SM, et al. Integrated model of primary and secondary eye care for underserved rural areas: the L V Prasad eye Institute experience. Indian J Ophthalmol 2012;60:396-400.

24 Marmamula S, Khanna RC, Kunkunu E, et al. Population-Based assessment of prevalence and causes of visual impairment in the state of Telangana, India: a cross-sectional study using the rapid assessment of visual impairment (RAVI) methodology. BMJ Open 2016;6:e012617.

25 Marmamula S, Narsaiah S, Shekhar K, et al. Visual impairment in the South Indian state of Andhra Pradesh: Andhra Pradesh - rapid assessment of visual impairment (AP-RAVI) project. PLoS One 2013;8:e70120.

26 Marmamula S, Challa R, Yellapragada S, et al. Temporal trends in the prevalence of spectacle use and spectacle coverage in India. Clin Exp Optom 2020;103:693-8.

27 Marmamula S, Khanna RC, Yellapragada S, et al. Temporal trends in the prevalence and causes of visual impairment in the South Indian state of Telangana: a population-based cross-sectional study. BMJ Open 2019;9:e029114

28 Marmamula S, Keeffe JE, Rao GN. Uncorrected refractive errors, presbyopia and spectacle coverage: results from a rapid assessment of refractive error survey. Ophthalmic Epidemiol 2009;16:269-74.

29 Marmamula S, Madala SR, Rao GN. Prevalence of uncorrected refractive errors, presbyopia and spectacle coverage in marine fishing communities in South India: rapid assessment of visual impairment (RAVI) project. Ophthalmic Physiol Opt 2012;32:149-55

30 Marmamula S, Khanna RC, Narsaiah S, et al. Prevalence of spectacles use in Andhra Pradesh, India: rapid assessment of visual impairment project. Clin Exp Ophthalmol 2014;42:227-34.

31 StataCorp. Stata statistical software: release 14. College Station, TX: StataCorp LP, 2014.

32 Hunter H, Shipp M. A study of racial differences in age at onset and progression of presbyopia. J Am Optom Assoc 1997;68:171-7.

33 Weale RA. Presbyopia and ambient temperature. Am J Optom Physiol Opt 1987;64:562-3.

34 Weale RA. On potential causes of presbyopia. Vision Res 1999;39:1263-72.

35 Weale RA. Epidemiology of refractive errors and presbyopia. Surv Ophthalmol 2003;48:515-43.

36 Nirmalan PK, Krishnaiah S, Shamanna BR, et al. A population-based assessment of presbyopia in the state of Andhra Pradesh, South India: the Andhra Pradesh eye disease study. Invest Ophthalmol Vis Sci 2006;47:2324-8.

37 Cunha CC, Berezovsky A, Furtado JM, et al. Presbyopia and ocular conditions causing near vision impairment in older adults from the Brazilian Amazon region. Am J Ophthalmol 2018;196:72-81.

38 Hickenbotham A, Roorda A, Steinmaus C, et al. Meta-Analysis of sex differences in presbyopia. Invest Ophthalmol Vis Sci 2012;53:3215-20.

39 Ramke J, du Toit R, Palagyi A, et al. Correction of refractive error and presbyopia in Timor-Leste. Br J Ophthalmol 2007;91:860-6. 